\title{
Consumer Safety and HACCP-Like Quality Risk Management Programs on Dairy Farms: The Role of Veterinarians
}

\author{
João Cannas ${ }^{*}$ and Jos Noordhuizen
}

\author{
VACQA-International, Santarém, Portugal
}

\begin{abstract}
Consumer safety is a matter of increasing concern, and is subject of continuous media attention as well as the general public attention. To assure that food products of animal origin are safe, the European Union has produced several directives, which will be compulsory in the near future. The HACCP (Hazard Analysis Critical Control Points) concept is not easy to implement on dairy farms because we are dealing with a complex production system including live animals, where the hazards and risks are manifold and highly diverse. The veterinarian should be pivotal to the program: contributing to the creation of the farm-HACCP team, willing to work with other professionals, and having sound knowledge of the production process. The application of this kind of program on dairy will ensure the safety of the food produced; protect animals and food from hazards during the production process before they pass beyond the physical limits of the dairy farm, to reach the next step in the food chain. Milk is a good example of a product that is already well controlled.

In this paper, we describe the seven HACCP principles embedded in the $12^{\text {th }}$ steps for developing a HACCP-like program. The HACCP concept cannot be fully applied, because:

(1) Animals show biological variation and hence no formal standards with tolerance limits can often be assigned.

(2) Most outcome parameters are based on diagnostic tests which do not show a $100 \%$ sensitivity or specificity, hence providing false-positive and false-negative results.

Most often on farms we can not define true Critical Control Points (CCP's) according to the formal criteria set and hence have to switch to Points of Particular Attention (POPA's) which do not meet all the CCP criteria but are still considered as critical in process control. Therefore, we talk about a HACCP-like program. The handbook of a HACCP-like Quality Risk Management Program is present and several examples are given. Some outcomes of risk hazards are present too. CCP's and POPA's are highlight with examples. The main objective of this paper is the to make the veterinarians aware of the expected evolution in ensuring consumers that food products originated on dairy farms are safe, and to show which role they should play in this development.
\end{abstract}

\section{INTRODUCTION}

Consumer safety has taken, over the last decades, an important position in our society, in particular in developed countries. The European Union (EU), as well other countries, has issued directives to ensure that the whole food chain is under control, and that food products from animal origin are safe for consumers. The final objective of the EU in this context will be the full implementation of the HACCP-concept and principles in the primary sector of production, in our case the dairy production units. Currently, the European consumers are sensitive to problems in areas like food safety and public health, as well as animal health and welfare to illustrate this; we only need to refer to BSE epidemic, the dioxin problems and the Salmonella survey in several species over the last years. European consumers have a great impact on animal production methods, and since the 1990 s, we observe an increasing pressure on the primary production sector, driving the producers to implement onfarm control programs [1-3]. European consumer concerns about food go far beyond the sole nutritional aspects or product quality issues, with the possibility of disease transmission being of major concern nowadays. Agents of concern include Salmonella, E. coli, and Listeria, to quote just a

*Address correspondence to this author at the VACQA-International, Santarém, Portugal; E-mail: joao.cannas@mail.telepac.pt few. As a result, the different sectors of production of food of animal origin are more and more active in developing and applying control activities, which should contribute to increase the consumer's confidence [4].

During the last years, the foundation has been laid for the implementation of programs that can meet the demands. The dairy farmers, as a first step in the dairy food chain, have to implement on-farm control programs enabling to show to authorities and consumers (retailers) that the public and animal health and welfare status of the herd is under control. The farmers also meet new challenges regarding environmental protection, and, hence, they need a support program, which can deal with all these different challenges...

A concept like Hazard Analysis Critical Control Points (HACCP), is the one quality control concept which best serves the objectives of both food safety and the farmers [4].

HACCP is a systematic method, preventive and sciencebased, which first priority is the safety of the products through risk identification and risk management in the production process. It has a proactive, rather than reactive approach, emphasizing food hazard prevention rather than the detection of harmful defects in finished food products. Its main objective is to identify problems before they occur, establishing control measures that are critical to maximizing food safety at each stage in the production process [4]. 
The applicability of this kind of program on the dairy farm is in ensuring the quality of the food produced (through managing the health and welfare of the animals) to protect cows and food from hazards, during the production process. Before, they pass beyond the physical limits of the dairy farm to reach the next step in the food chain [4].

The HACCP concept is already very common through the food chain and used in different areas such as restaurants, transports, food and feed production units. Veterinarians have an important role in supporting the implementation of the HACCP concept on farms because given their educational background and field experience they are the few professionals with knowledge, understanding and experience in feed, animals, productivity, food and management.

We speak about a HACCP-like program are that (1) on farms we deal with living animals with their biological variation and physiological processes, (2) most outcome parameters are based on diagnostics with sensitivities and specificities not reaching the $100 \%$ and hence leading falsepositive and false-negative results, (3). With live animals we commonly do not have standards with tolerance limits, like in physical processes but rather have target values (e.g. the clinical mastitis rate per year as a target could be set at $<$ $25 \%$ ), and (4) hence have few CCP's but many POPA's, because formal CCP criteria can not often be met and yet we need to control critical issues in the production process.

Before discussing the role of veterinarians in the HACCP development and implementation on dairy farms, we will first highlight the principles of the HACCP concept embedded in the 12 developmental steps. Subsequently, we will follow the respective chapters of a HACCP-like handbook to explain the development and implementation in some more detail.

After knowing the principles and the developmental steps (Table 1), we now introduce the Handbook of a HACCPlike Quality Risk Management Program (QRMP), because from the various chapters we can see which pathway to follow to develop and implement the HACCP-components.

\section{THE HANDBOOK OF A HACCP-LIKE QUALITY RISK MANAGEMENT PROGRAM}

This handbook comprises, after identification of the farm and the members of the HACCP-team, the following components:

1. Production process diagram and identification of the different steps in the production process;

2. Hazard analysis chart

Refers to the respective steps, as well as the inputs, where main hazards could happen leading to quality problems (e.g. water contamination; microbial contamination); general preventive measures already taken; and the impact of the risk to human health; all for each step. Risk assessment!

3. Hazards audit table (identification of CCP's and POPA's; monitoring; measures)

Refers to each operational activity, the potential hazards, CCP's and POPA's, screening or check points, monitoring procedures, critical limits \& standards, or targets, corrective actions per CCP or POPA, records

4. Registration requirements, statements like Good Veterinary Practices (GVP), Good Dairy Farming Practices (GDFP), and Good Manufacturing Practices (GMP), the farmer's own declaration

Refers to declarations of those professionals who are active within the Quality Management Program, e.g. veterinarian, inseminator, feed mill nutritionist, stating to comply with the rules set within the Quality Management Program, as well as to the declaration of the farmer himself stating that he will comply with the rules set out in the law and that activities are carried out according to the program specifications. The latter also applies to farm-workers.

5. Support programs. These comprise on-farm guidelines and work instructions for specific areas on the

Table 1. Developing the HACCP-Like Program and Implementing the HACCP-Principles in 12 Steps; Adapted from [5]

\footnotetext{
1. Assemble a multidisciplinary, facility-based, HACCP-team (e.g. farmer; veterinarian; nutritionist and/or farm-economist).

2. Describe the final product and the method of distribution (e.g. formulation, processing requirements).

3. Identify the intended use of the (raw) food product and the targeted purchaser.

4. Develop a flow diagram that describes the production and distribution process (a production process decomposition diagram). Work from whole-farm level to the production step levels (e.g. milk harvesting; feeding procedures).

5. Verify the flow diagram on-site on correctness with the farm-workers.

6. Implement Principle 1: Prepare a list of steps in the production process at which targeted hazards occur. Identify these main hazards and their associated risk factors.

7. Apply Principle 2: Identify the critical control points, (CCP's), in the production process required to reduce or eliminate the hazard. Identify the points of particular attention, (POPA's).

8. Apply Principle 3: Establish standards and critical limits, or targets, for triggering the implementation of corrective/preventive measures associated with each CCP or POPA identified when control is lost.

9. Implement Principle 4: Establish monitoring requirements for each CCP and POPA. Use the results of the monitoring program to adjust the procedures and to maintain control of the production process. Use monitoring also for herd performance assessment.

10. Apply Principle 5: Determine corrective measures, to take when monitoring indicates that a value falls outside the established critical limits or beyond a given target.

11. Apply Principle 6: Establish effective record-keeping procedures that document that the HACCP program was implemented, and is operational.

12. Apply Principle 7: Establish procedures to verify that the HACCP-like program is working correctly (e.g. internal reviews and external verification, periodic revalidation of the system).
} 
farm. This also refers to on-going herd health programs.

Among others refer to personal hygiene and health of workers, dress/boot code, handling of hazardous materials, handling of waste materials, handling hotspots regarding cross-contamination, hygiene and disinfection of equipment and vehicles, equipment and vehicle maintenance, calibration of measuring and dosing devices, good administration of medicines, good colostrum management. These issues are further described in technical work instructions (protocols).

6. Training programs for farmer and/or coworkers, prepared by the veterinarian or other specialists.

Training should be recorded on a separate sheet. Regularly the training needs of the farm have to be revisited. Training is carried out on-site and is of short duration.

7. Internal Reviews by the HACCP team and external audits by technically trained people.

An internal review (focus on effectiveness and compliance) is to be carried out annually for each worker by using a checklist. An annual review of the $Q R M P$ handbook, using a checklist, should be performed next; this review should ensure that all procedures are up-to-date, documented, numbered and authorize, with old documents being archived. Findings, corrections and improvements are to be listed on sheets, and archived. An external audit is to be carried out annually (focus on integrity).

8. Documents and document control.

To be retained for 2 years. Examples: guidelines, instructions, delivery complaint report, purchase forms (e.g. medical products), order forms, training sheet, calibration report, laboratory results report, disease logs, internal audit report, external audit report, QMP handbook review.

At this stage, the veterinarian takes the lead in creating the so-called production process diagrams.

\section{Production Process Diagrams (Step 4 in Table 1; Chapter 1 of the Handbook)}

Production process diagrams are schematic representations of the production process on a dairy farm. It is advisable that these diagrams where drawn on-site with farmer and farm-workers, and then their correctness is verified on farm. The basic idea is to work from the larger picture downwards to the smaller images with more detail. For example, beginning in the main farming areas and going down of the milk-harvesting phase. All process steps should fit one DIN $\mathrm{A}_{4}$ page in order to keep it readable. These diagrams appear to be very helpful in understanding what is happening where and they support the discussion in the HACCP-team clarifying for farm-workers where hazards, risks, tasks and responsibilities are. Some examples are given here (Figs.1,2). Take good notice about the level they have assigned to: overall farm-level, parts of the farm, or details of

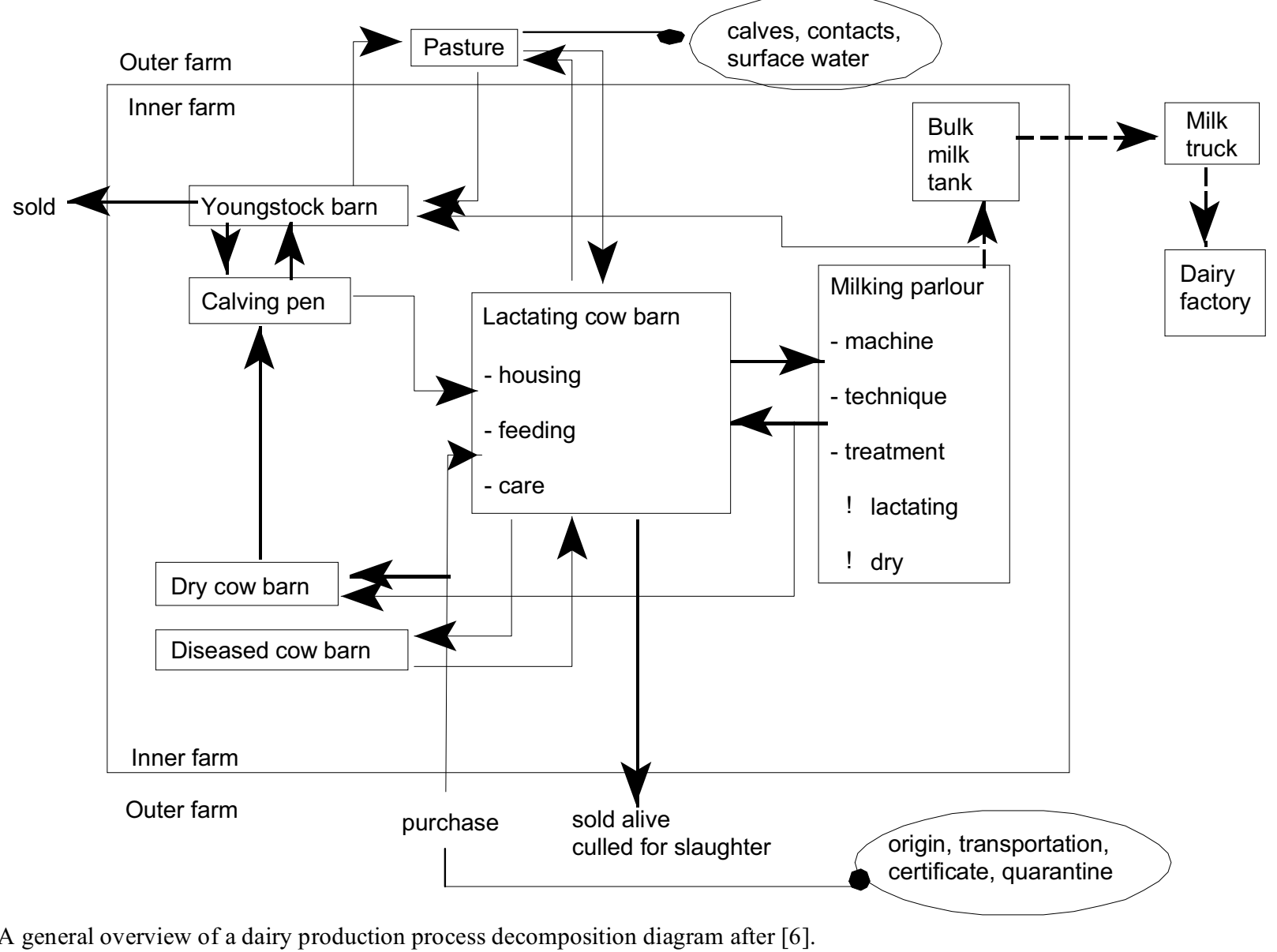

Fig. (1). A general overview of a dairy production process decomposition diagram after [6]. 


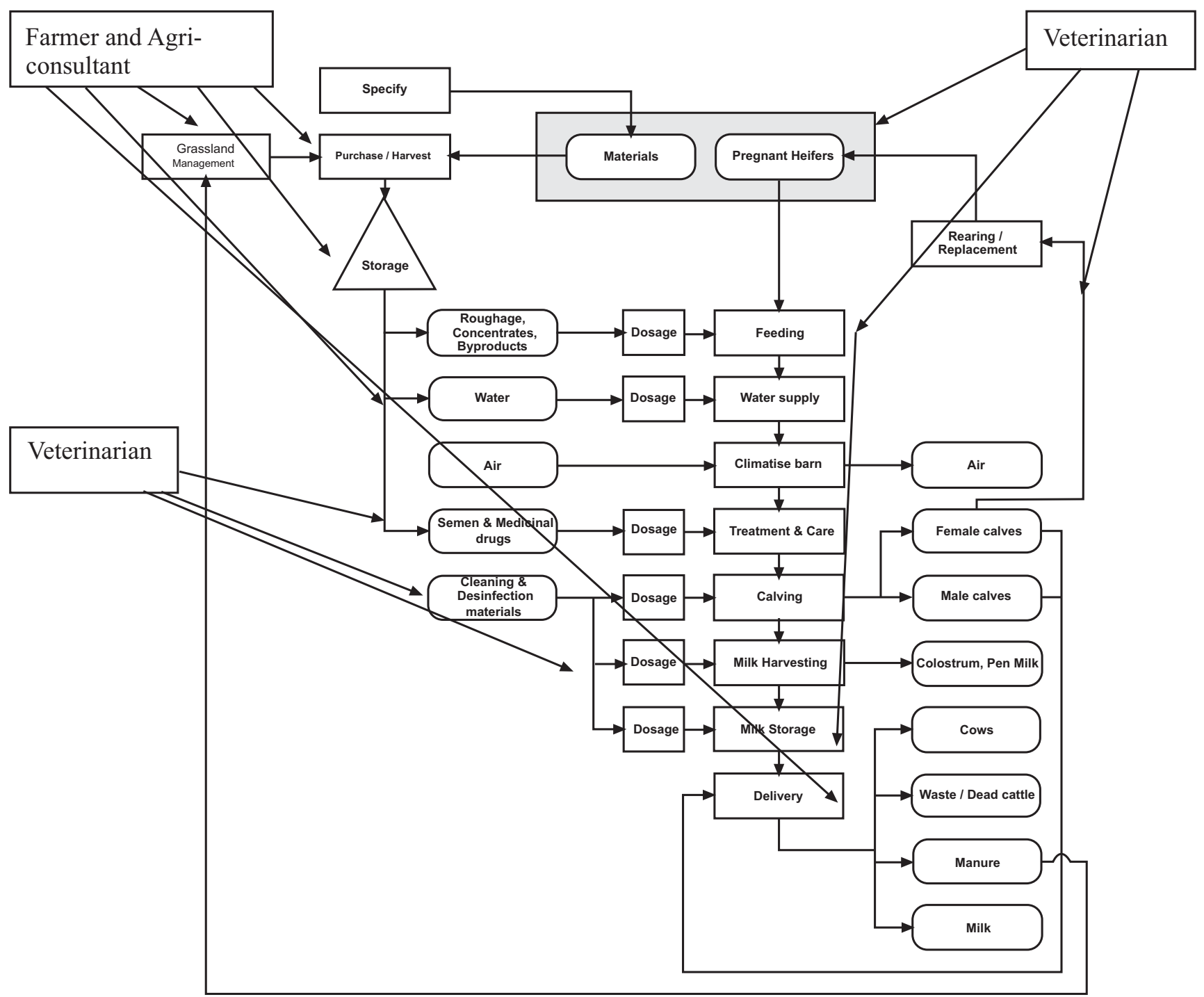

Fig. (2). An example of a detailed production diagram on one particular farm, referring to the process steps of feeding and feeding management; after [7].

processes. The veterinarian has the knowledge and skills to contribute to the design of these diagrams - he could very well have such example diagrams in his office PC ready for adjustment to a particular farm, and then discuss the result with the farmer and farm - workers.

\section{Hazards \& Risks Analysis Charts (Step 6 in Table 1; Chapter 2 of the Handbook)}

The hazards and risks associated with disorders in the area of animal health, animal welfare, food safety and public health can be identified by using the strengths-andweaknesses assessment (SWA) sheets, provided as provided foe example on the www.vacqa-international.com web site. If they are not available for a certain specific area, one may develop a new SWA with the help of the SWA sheet examples already given, because they provide a blueprint of such an approach.

Discussions between veterinarian and farmer and with the nutritionist or farm-economist will help to prioritize the most important hazards. Weighting of risks can be done using quantitative epidemiologic information or by the onfarm, HACCP-team through assigning weighing factors to the different risk conditions. The latter weighting is qualitatively conducted through estimating the probability (P) of occurrence and the impact (I) $(=\mathrm{P} * \mathrm{I})$; hence, the so-called true risks can be identified and addressed later on. Examples of such a risk weighting are given in Tables 2 and $\mathbf{3}$. These charts can be available in the veterinarian's office in digital format.

\section{The Definition of Formal CCP's (Step 7 in Table 1; Chapter 3 of the Handbook)}

To determine whether a control point has formally defined as 'critical' we use the decision-tree scheme as given in Fig. (3). True, i.e. formal, critical control points, CCP, have to meet certain formal criteria (see next paragraph). If a critical point is not a true, formal CCP, it still defined as a POPA when considered truly relevant for process control. The veterinarian is the one who answers the respective questions by discussing the outcomes in the HACCP team. 
Table 2. Outcome of Risk Estimates Regarding the Physical and Chemical Hazards of Milk Quality - An Example

\begin{tabular}{|c|c|c|c|c|c|c|c|c|c|}
\hline \multirow{2}{*}{ Code } & \multirow{2}{*}{$\mathrm{C} / \mathbf{P h}$} & \multirow{2}{*}{ Hazard } & \multirow{2}{*}{$\begin{array}{c}\text { Process Step } \\
\text { M=Milking } \\
\text { T=Treatment }\end{array}$} & \multicolumn{3}{|c|}{$\begin{array}{l}\text { Weighting } \\
P \text { and I }\end{array}$} & \multirow{2}{*}{$\begin{array}{l}\text { Risk } \\
\text { Yes/No }\end{array}$} & \multirow{2}{*}{ CCP/POPA } & \multirow{2}{*}{$\begin{array}{c}\text { Prevention/Control Measure } \\
\text { (Farmer Focused) }\end{array}$} \\
\hline & & & & $\mathbf{P}$ & I & $P * \mathbf{I}$ & & & \\
\hline $\mathrm{T}_{1}$ & $\mathrm{C}$ & Wrong drug & $\mathrm{T}$ & 2 & 2 & 4 & No & POPA & $\begin{array}{l}\text { Proper diagnosis } \\
\text { Check label } \\
\text { Drug advisory plan } \\
\text { See datasheet }\end{array}$ \\
\hline $\mathrm{T}_{2}$ & $\mathrm{C}$ & Residue in meat & $\mathrm{T}$ & 1 & 2 & 2 & No & POPA & $\begin{array}{l}\text { Withdrawal time } \\
\text { Drug advisory plan } \\
\text { See instruction leaflet }\end{array}$ \\
\hline $\mathrm{T}_{3}$ & $\mathrm{C}$ & Wrong dosage & $\mathrm{T}$ & 2 & 2 & 4 & No & POPA & $\begin{array}{l}\text { Check proper dosage } \\
\text { Use drug advisory plan }\end{array}$ \\
\hline $\mathrm{T}_{4}$ & $\mathrm{C}$ & Drug over shelf life & $\mathrm{T}$ & 2 & 1 & 2 & No & GFP & $\begin{array}{l}\text { Check shelf life } \\
\text { See datasheet }\end{array}$ \\
\hline $\mathrm{T}_{5}$ & $\mathrm{C}$ & Cows' ID fails during withdrawal & $\mathrm{T}$ & 2 & 3 & 6 & Yes & $\mathrm{CCP}$ & See datasheet \\
\hline $\mathrm{T}_{6}$ & $\mathrm{Ph}$ & Needle broken & $\mathrm{T}$ & 1 & 1 & 1 & No & GFP & Inject with care \\
\hline $\mathrm{M}_{1}$ & $\mathrm{C}$ & Drug residues in milk & M & 2 & 3 & 6 & Yes & $\mathrm{CCP}$ & $\begin{array}{l}\text { Good cow ID } \\
\text { Withdrawal time } \\
\text { Stick to indications } \\
\text { See datasheet }\end{array}$ \\
\hline
\end{tabular}

$\mathrm{T}_{\mathrm{i}}=$ treatment step in the process; $\mathrm{M}_{\mathrm{i}}=$ milk harvesting step in the process; $\mathrm{C}=$ chemical; $\mathrm{Ph}=$ physical; $\mathrm{CCP}=$ critical control point; $\mathrm{POPA}=$ point of particular attention; $\mathrm{P}=$ probability; I= impact; ID= identification.

Table 3. Outcomes of Risk Estimates of Microbiological Hazards During Milk Harvesting, an Example of one Particular Farm

\begin{tabular}{|c|c|c|c|c|c|c|c|c|}
\hline \multirow{2}{*}{ Hazard } & \multirow{2}{*}{ Process Step } & \multicolumn{3}{|c|}{ Risk Estimate } & \multirow{2}{*}{$\begin{array}{l}\text { True Risk } \\
\text { Yes/No }\end{array}$} & \multirow{2}{*}{$\begin{array}{l}\text { CCP/ } \\
\text { POPA }\end{array}$} & \multirow{2}{*}{$\begin{array}{l}\text { Prevention/Control } \\
\text { Measures }\end{array}$} & \multirow{2}{*}{$\begin{array}{c}\text { Responsi- } \\
\text { ble } \\
\text { Person }\end{array}$} \\
\hline & & $\mathbf{P}$ & I & $P * I$ & & & & \\
\hline Milk with B. abortus & $\mathrm{T}, \mathrm{M}$ & 1 & 2 & 2 & No & GFP & $\begin{array}{l}\text { Certificate free of B. abortus } \\
\text { High hygiene level }\end{array}$ & Farmer \\
\hline Milk with Mycob. bovis & $\mathrm{T}, \mathrm{M}$ & 1 & 3 & 3 & No & GFP & Certificate free of $M$. bovis & Farmer \\
\hline Milk with L. monocytogenes & $\mathrm{T}, \mathrm{M}, \mathrm{BT}, \mathrm{C}, \mathrm{F}$ & 2 & 4 & 8 & Yes & $\mathrm{CCP}$ & $\begin{array}{l}\text { Hygiene at milking } \\
\text { Infected cows separate } \\
\text { Reduce infection spread }\end{array}$ & Farmer \\
\hline Milk with $S$. dublin/typhimurium & $\mathrm{T}, \mathrm{M}, \mathrm{F}, \mathrm{C}$ & 1 & 3 & 3 & Yes & POPA & $\begin{array}{l}\text { Hygiene at milking } \\
\text { Increase health status }\end{array}$ & Farmer \\
\hline Milk with $C$. jejuni & $\mathrm{T}, \mathrm{M}, \mathrm{C}$ & 2 & 2 & 4 & Yes & POPA & Hygiene at milking & Farmer \\
\hline Milk with Staph. aureus & $\mathrm{T}, \mathrm{M}$ & 3 & 2 & 6 & Yes & $\mathrm{CCP}$ & $\begin{array}{l}\text { Cows with infection to be } \\
\text { separated; reduce } \\
\text { infection spread (see drug } \\
\text { advisory plan \& instruction } \\
\text { leaflet) }\end{array}$ & Farmer \\
\hline Milk with E. coli $\mathrm{O}_{157} \mathrm{H}_{7}$ & $\mathrm{~T}, \mathrm{M}, \mathrm{C}$ & 2 & $3 ?$ & 6 & Yes & $\mathrm{CCP}$ & Hygiene at milking GFP & Farmer \\
\hline Milk with $Y$. enterocolitica & $\mathrm{T}, \mathrm{M}, \mathrm{C}$ & 1 & 2 & 2 & No & GFP & Hygiene at milking GFP & Farmer \\
\hline
\end{tabular}

$\mathrm{T}=$ treatment step in process; $\mathrm{M}=$ milk harvesting step; $\mathrm{F}=$ feeding step; $\mathrm{C}=$ barn climate step; $\mathrm{BT}=$ bulk milk tank; $\mathrm{GFP}=$ good farming practice guideline; $\mathrm{CCP}=$ critical contro point; $\mathrm{POPA}=$ point of particular attention.

\section{Explanation to CCP's and POPA's}

Critical Control Points (CCP) and Points of Particular Attention (POPA) are usually derived from the risk conditions found in earlier steps of the HACCP-like program development.

CCP's have to meet the following formal, five criteria:

- be associated with the hazard of concern,

- be measurable or observable,
- have norms/standards and tolerance limits,

- be accompanied by corrective measures which,

- must fully restore control, once it is lost.

Usually, costs: benefit calculations should be associated with the alternative corrective measures considerer allows for least cost interventions and optimal integration with farm management. POPA's fail to meet at least one of the forenamed CCP-criteria, namely because they lack formal standards or because they are not fit to fully restore control. 




Fig. (3). Decision-tree approach to determine which control points can be considered as true, formal, critical control points, (CCP).

Sometimes they are called CCP-2 but we prefer the sharper distinction of POPA with true, formal CCP.

An issue of concern relates to the standards and tolerance limits for CCP in livestock production. Physical features and processes are commonly provided with standards and tolerance limits, for example, the temperature of the cleaning water for rinsing the milking machine can be set at $80{ }^{\circ} \mathrm{C}+-$ $2^{\circ} \mathrm{C}$. However, in the case of biological processes with live animals we deal with biological variation among animals and in diagnostic tests, we deal with false positive and falsenegative test results and variable, arbitrary cut-off points. In such situations, we cannot speak about standards, but should rather introduce the term "targets" or reference values. For example, the target for clinical mastitis cases can be set at $<$ $25 \%$ per year. Each POPA must have assigned such a target value.

The Monitoring of CCP's and POPA's (Step 9 in Table 1; Chapter 3 of the Handbook)

The CCP's and the POPA's are to be put into a monitoring scheme for the dairy farm. In this scheme, the items for monitoring, as well as their frequency, the method of monitoring and the person responsible for monitoring must be listed. 
Table 4. An Example of a Monitoring Table in a HACCP-Like QRM

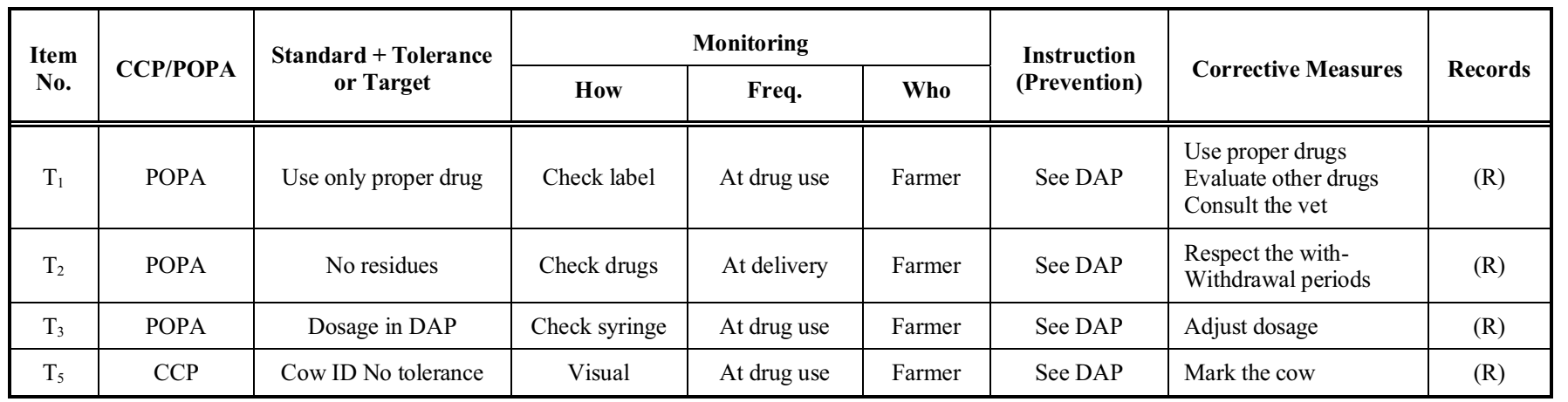

$\mathrm{T}_{\mathrm{i}}=$ cow treatment step in the process; POPA = point of particular attention; $\mathrm{CCP}=$ critical control point; DAP $=$ drug advisory plan of the veterinarian for the herd; $(\mathrm{R})=$ drug application records; ID = identification of cow.

An example of part of a HACCP-like QRM program on a dairy farm for chemical and physical hazards in the process step of cow treatment $T_{i}$ (see also the general production process diagrams) is given in Table 4. The veterinarian has the responsibility in the program to design the drug advisory plan and keep it updated. The veterinarian also does the evaluation of the drug use (e.g. efficacy; cost: benefit, duration of treatment) and conducts a screening on items monitored during the farm visits.

\section{Support Programs (Step 10 in Table 1; Chapter 5 of the Handbook)}

In addition to on-going herd health programs or biosecurity plans being both supportive to the HACCP-like QRM, we will focus here on guidelines and work instructions. The statements named in chapter 4 of the Handbook (GVP, GFP, $G M P)$ will not be further addressed here.

Good Dairy Farming codes of practice, (management guidelines for daily farm practice).

Good Dairy Farming (GDF) codes of practice are general management guidelines for farmer and farm workers meant to improve farm performance, and for professional visitors to comply with the rules set on the farm. These guidelines are derived from the Good Agricultural Practice (GAP) guidelines as provided by a joint FAO - OIE committee [8], for the areas of animal production, animal health and welfare. There can be multiple GDF guidelines: their development and implementation depends on the need for them [8].

Good dairy farming guidelines can be developed at each point in the production process of the dairy farm, for those areas where certain hazards can occur, helping to create or improve awareness among the people involved (their attitude and mentality focus), and highlighting responsibilities. When the veterinarian has a series of elaborated examples of such guidelines in a digital format, he can easily adapt those to the particular needs of an individual dairy farm.

Examples of such guidelines under the heading of Good Dairy Farming codes of practice are:

Good Farm Hygiene and Disinfection codes of practice,

Good Medicine Application code of practice,

Good Feeding Management code of practice,

Good Milking Hygiene code of practice,

\section{Good Calf Rearing Code of Practice}

In the evolution of risk assessment, we can find several risk factors, which are highly disease-specific, and other risk factors that are common to several disorders. We will usually find the latter, more general, risk factors in the GDFguidelines, which are meant to improve awareness. Examples are hygiene issues on the farm, the role of the milking machine, the milking routine. Although these guidelines are very general in nature, the veterinarian should strive to specify them as much as possible to the individual farm conditions and install them if needed. Below we will elaborate in more detail several technical work instructions on hygiene, associated with several areas on the dairy farm, as examples.

\section{Good Hygiene Code of Practice on Dairy Farms: Some Work Instructions}

Dairy farming is about producing raw materials for food processing: milk (and beef). Therefore, the cleaning, disinfection and maintenance of areas where such raw materials are being produced (milking parlour) or stored (bulk milk tank) must meet the highest demands. Hygiene activities should follow strict rules. In these technical work instructions, the different elements relevant for cleaning are addressed as well as their rationale. Commonly, hygiene practices are not described, but rather exist in farmers mind in a more or less variable way. Describing the different components not only makes the farmer more aware of the actions he/she is taking. Ultimately, by describing the hygiene work instructions, it can be showed to third parties that the dairy farm is indeed taking hygiene seriously as one way to safeguard milk production and food safety from chemical and microbiological contamination. These work instructions on hygiene are of a blue print type, meaning that they have to be further specified for each individual farm; in some cases by deleting items, in others by adding them. The veterinarian should have those work instructions in digital format, which he can adapt to specific conditions. They can, also be regarded as a checklist for consulting afterwards. The basis for these working instructions is in scientific evidence and field experience.

\section{Procedure for Cleaning; The Milking Parlor}

There are 6 steps in the cleaning procedure to be followed:

- $\quad$ pre-treatment (in order to eliminate loose dirt mechanically);

- $\quad$ cleaning (to loosen dirt by applying certain products); 
- $\quad$ rinsing (to eliminate loosened dirt and neutralize cleaning product residues);

- $\quad$ disinfection (to destroy bacteria that survived cleaning by applying disinfectants);

- $\quad$ rinsing (to eliminate residues of disinfectants);

- $\quad$ drying (to eliminate the last rinsing water).

These 6 steps are integrated into 3 working methods, depending on the areas, where more or less contact may exist with the raw food being produced. These methods are:

\section{[A] Cleaning and Drying}

For areas where no direct contact exists between surfaces to be cleaned and raw material (e.g. milk) being produced on the farm.

\section{[B] Cleaning, Rinsing \& Drying}

For areas, materials and equipment where contact with residues of cleaning products with raw material (e.g. milk) must be avoided.

\section{[C] Cleaning, Rinsing, Disinfection, Rinsing and Drying}

For surfaces of equipment and materials which are in direct contact with the raw material being produced (e.g. milk) and which are not subjected to heat-treatment.

\section{Hygiene Rules to be Followed}

In addition to the application of the methods described above in the paragraph "Procedure for Cleaning", the farm worker(s) responsible for executing hygiene measures should strictly follow some rules. These rules, part of Good Dairy Farming Practice, include:

- $\quad$ the instructions given should be strictly followed

- $\quad$ personal hygiene of the people involved is a prerequisite (clean hands/nails; clothes; boots)

- $\quad$ parts of equipment which can be disassembled, should be regularly subjected to cleaning/disinfection (e.g. milking machine)

- $\quad$ in case of purchase of a new equipment or in situations of reconstruction, working hygienically remains paramount

- $\quad$ in case of replacing certain parts, mounting instructions must be strictly followed

working instructions on hygiene must be executed......

o on the right moment,

- with adequate frequency,

- using adequate dosage of products,

- while using clean materials,

- without neglecting rinsing/drying after cleaning and disinfection.

- while allowing for a stand alone period

\section{Check Points in the Cleaning/Disinfection Procedure}

In order to provide the farmer with the certainty that the effects of cleaning and disinfection procedures are being achieved, it is worthwhile to insert a few checkpoints in the whole procedure. These check points are also part of Good Dairy Farming practice.

Examples of checkpoints are:

Timing of the cleaning/disinfection: should not be conducted during moments that the raw material (e.g. milk) is being produced, so not during milking time.

- $\quad$ Proper dosage of cleaning/disinfection products: too low dosage will negatively affect the effect; a too high dosage is too expensive and environmentally undesired.

- Clean the working materials in order to prevent recontamination.

Duration of the different steps and procedures: disinfection should last at least 5 min to be effective.

Rinsing after disinfection of surfaces in contact with e.g. milk is needed to avoid contamination of milk by product residues.

Separation of dirty and clean parts of equipment, materials and surfaces in order to avoid re-contamination and insufficient cleaning.

Check refrigeration temperature or boiling temperature and bulk tank temperature daily..

- $\quad$ Do not store chemical products close to the bulk milk tank.

- $\quad$ Keep refrigerator free of ice and do not turn it off.

- Check regularly the expiration date of cleaning and disinfection products.

- Safeguard limitations/requirements with respect to temperature, $\mathrm{pH}, \mathrm{UV}$ exposure, water hardness when using cleaning/disinfection products.

Special attention must be given to professional and lay visitors, because, potentially, they represent a risk of introducing or spreading pathogens into and on the farm. In the next paragraph we will present some details.

\section{Check Points for Visitors (Professional and Lay People)}

General checkpoints for the first implementation of a work instruction on hygiene regard the issues named in Table 5.

Once these general hygiene issues have been addressed and adjusted when needed, the Hygiene Instruction for Visitors can be implemented. It is best that farmers put that instruction on a board at the entrance and or give it to those professional visitors that come to his farm most frequently. An example of a farm $\mathrm{F}$ is presented below.

\section{Hygiene Instruction for Visitors to Farm F \\ Welcome to our dairy farm!}

We expect you to strictly follow the instructions on hygiene listed below; thank you!

1. Cars and trucks

2. Use only the parking place as indicated on the map by P. 
3. Change your boots and clothes in the hygiene barrier (see map on your left hand side) before entering our farm. Report your arrival by using the phone as indicated.

4. If you need to make contact with animals on our farm, take along disposable gloves. If needed, use the available farm equipment and not your own.

5. Upon entry to the farm, the farmer or someone in is behalf will tell you the working order of the farm. At all times, follow our hygiene instructions.

6. Follow the routine working order of the farm. Use disinfection tubs wherever they are present; change clothes/boots and wash hands whenever this is indicated.

7. Do not make contact with our cattle, pets and other animals, if not necessary.

8. Clean the boots when the farm visit has ended, All materials introduced on our farm are considered to be dirty materials (irrespective of being used or not) and should not be used on other farms. Change clothes and boots, dispose of gloves, wash your hands thoroughly.

9. Record medicinal products which have been used and or delivered in the MEDICINES' Log, and

10. Register date/your name/ time in the VISITORS' Log.

11. Delivered medicinal and other products should be stored in the right place as indicated on the map or handed over to the farmer.

Thank you for your visit and thank you for complying with these rules! You have contributed to minimizing the risk of introducing pathogens into our dairy farm.

We hope to see you again!

- - - - - - - . - -
The hygiene barrier at the entrance of a farm is one of the first levels of defense in biosecurity. Equipment, cars, and trucks from third parties (inseminator, hired labor, cooperative staff, hoof trimmer; veterinarian etc) as well as the people themselves are potential sources from the introduction of micro-organisms to the farm, for example through manure. In principle, they should stay at the dirt side of the farm. The visitors deserve particular attention and have been addressed above. In the next Table 6 we address the hygiene in the hygiene barrier by presenting a checklist.

By entering a date in a respective box, farmers have the overview of the actions planned and taken; moreover, it shows the visitors which activities farmers have conducted to contribute to higher hygiene standards. Items can be added when wanted.

\section{Hygiene Measures in the Milking parlour and it's Envi- ronment}

The most direct contact between the raw material (milk) being produced and the environment of production occurs in the milking parlour. Particular attention with regard to highest hygienic standards has therefore to be given to this site in order to prevent milk from becoming contaminated. It must be common practice that the milking machine maintenance and evaluation take place at least every 6 months by a certified technician. A written evaluation report indicating the findings, including defects and repairs, must be provided at each machine check up. Milking machine evaluation must be conducted with the machine in full action, the so-called "wet evaluation". Only then, potential failures in functioning can be detected properly. A proper milking machine function provides the best way to obtain the milk from the cows' udder, and minimizes the risk of pathogen transmission to and micro-trauma in teats and quarters, hence limiting the risk of udder infections (mastitis and contamination of milk). Clean milking equipment is meant to keep low. bacteria counts in milk For that purpose critical components need to be checked at regular intervals; screening for dirt and calcifica-

Table 5. Some Relevant Issues for Checking the Hygiene Elements Related to Visitors

\begin{tabular}{|l|c|c|}
\hline & YES & NO \\
\hline \hline Does the farm have a disinfection tub for cars? & $\mathrm{O}$ & $\mathrm{O}$ \\
\hline Is there a specific parking place for professional visitors? & $\mathrm{O}$ \\
\hline Is the parking place on the dirt part of the farm? & $\mathrm{O}$ & $\mathrm{O}$ \\
\hline Is clearly indicated the entrance to the farm? & $\mathrm{O}$ & $\mathrm{O}$ \\
\hline Have been clearly identified barns/sites? & $\mathrm{O}$ & $\mathrm{O}$ \\
\hline Is there present a hygiene barrier? & $\mathrm{O}$ & $\mathrm{O}$ \\
\hline Is the hygiene barrier well located? & $\mathrm{O}$ \\
\hline Is the hygiene barrier well equipped? & $\mathrm{O}$ \\
\hline Is functional the hygiene barrier? & $\mathrm{O}$ & $\mathrm{O}$ \\
\hline Is the on-farm working order from young to older cattle? & $\mathrm{O}$ & $\mathrm{O}$ \\
\hline Are there clean boots and clothes per barn provided? & $\mathrm{O}$ \\
\hline Does every barn have its own materials/instruments? & $\mathrm{O}$ \\
\hline Are there different sites to wash hands? & $\mathrm{O}$ & $\mathrm{O}$ \\
\hline Na= not applicable. & $\mathrm{O}$ \\
\hline
\end{tabular}


Table 6. An Example of Checklist for Cleaning the Hygiene Barrier

Remind that the Hygiene Barrier is Meant to Prevent Introduction of Pathogens!

\begin{tabular}{|c|c|c|c|c|}
\hline & Daily & Twice/Week & Once/week & Monthly \\
\hline Clean towels & - & & & \\
\hline Check boots on cleanness and dryness & - & & & \\
\hline Clean washing tub & - & & & \\
\hline Empty the dustbin, clean and dry it & & - & & \\
\hline Empty the storage of chemical waste, clean and dry it & & - & & \\
\hline Empty the storage of needles, clean and dry it & & - & & \\
\hline Clean the floor, disinfect, rinse, dry it & & - & & \\
\hline Check delivery log, add new pages & & & - & \\
\hline Empty the refrigerator, clean, rinse, disinfect, rinse, dry it & & & & - \\
\hline Empty the whole hygiene barrier, clean, rinse, disinfect, rinse, dry it & & & & - \\
\hline Check expiration dates of the cleaning products and disinfectants & & & & - \\
\hline
\end{tabular}

Hang this Checklist Inside the Hygiene Barrier; List the Dates of Execution of Actions

tion is part of this procedure. Droplets on surfaces may point to dirt or fatty bio-film.

Machine cleaning procedures may be checked on the following elements:

Boiler temperature at start of cleaning procedure (at least $80^{\circ} \mathrm{C}$ )

Boiler temperature at end of cleaning procedure (at least $40^{\circ} \mathrm{C}$ )

Proper dosage of chemical cleaning products

Volume of water needed for the cleaning process

Distribution of cleaning fluids over milking clusters

It should be stressed here that standard cleaning products (containing alkali products) destroy bacteria by disinfection and removes milk deposits, while acidic products clean and removes calcifications; rules set by the dealer must be followed. Rubber teat liners and long milking tubes must be replaced after every 2500 milkings, while silicon teat liners need to be replaced after every 5000 milking.

Checklists are available for monitoring the hygiene measures taken in and around the milking parlour, as well as for the milking machine. The farmer should realise that this is the place where he earns his income and therefore, highest priority must be given to the hygiene standards. Checklists are also available for exploring increasing bacteria counts in bulk tank milk. Contributing risk factors should be evaluated on their impact and adequate measures defined. Once the causal factors are found and intervention is conducted, we should evaluate the outcome and adjust when needed.

\section{Other Hygiene Measures}

The milkers who are responsible for the routine milking have a particular task in the whole process. They are the ones who are in direct contact with the animals, their udder and milk, and the milking machine. They may play a role in the transmission of udder pathogens when personal hygiene is not optimal, they play a role in proper milking machine handling, and they are responsible for good udder preparation, milking and sanitation procedures.

In case there are doubts about the proper milking method applied, it is recommended to make a time study of milking on a sample of the lactating cows. In such a time study, the respective intervals in seconds or minutes between all milking-related actions per cow are recorded and compared to reference values for a group of cows.

To be sure that cleaning products meant for hygienic purposes delivered to the farm are in good order, they should be checked upon delivery. They should be checked for:

expiry date

condition of the packaging material,

products in the invoice and actually delivered

having been recorded in the respective LOG or archiving the bill 
need products to be stored in a refrigerated environment,

delivered products should never be put directly on the floor.

Another issue of hygiene that deserves attention is the hygiene and cleanness of feeding alleys and exercise areas and especially those where crossing of people, animals, trucks or other occur (high-risk spots for pathogen transmission).

Moreover, proper and hygienic manure storage is a relevant issue for safeguarding the farm from becoming contaminated.

A further area of concern may be the equipment and people from outside the farm providing services on the farm (e.g. feed harvesting, manure spreading). They may not only introduce or spread pathogens into/on the farm but also from farm to farm. These people and their equipment must comply with the hygiene rules set by the farmer.

The forenamed "risk groups" can be provided with particular work instructions; such instructions can be found in detail in [7].

\section{Other Support Materials in the Quality Risk Management Program: The Farm Calendar}

In addition to the formal QRM-sheets presented above, QRM support materials can be very useful to the dairy farmer and his farm-workers because they focus attention of certain points in the production process where regular checking is needed, for example based on previous farm problems. They contribute to awareness and motivation, timely action and provide discussion between farmer and veterinarian. The veterinarian initiates this discussion during farm visits. An example is the farm calendar with seasonal issues, which repeatedly are addressed on the farm. Table 7 comprises such a farm calendar for one particular dairy farm. Again, the veterinarian has the digital format of such calendar; he can easily adapt it to the specific needs of a particular farm.

Training Programs in the Quality Risk Management Program (step 10 in Table 1; Chapter 6 of the Handbook)

In certain conditions - for example on large dairy farms with several farm-workers - it can be highly indicated to organize specific training programmes for all or some farmworkers in specific farming domains. These trainings must be of short duration and be done on-site to have the deepest impact.

Examples of training programmes are those on: claw trimming and diagnosis of claw lesions; diagnosis of clinical and subclinical mastitis; proper milking procedures; on-farm hygiene; biosecurity plans; colostrum management; calf rearing systems.

\section{Internal Reviews and External Audits in the Quality Risk Management Program (Step 12 in Table 1; Chapter 7 of the Handbook)}

Internal reviewing or validation is needed at least once every year to make sure that the HACCP-like QRM-program is running adequately. Based on the internal reviewing, adjustments might be needed, new elements or records added and old elements eliminated from the handbook and ar- chived. The evaluation of herd performance figures in the different farm domains and the comparison with those of previous year(s) and or other farms may indicate the stronger and weaker points on the farm, as well as the extent to which progress has been made. For the latter purpose, the SWAsheets on the vacqa-international.com website can be used. If needed, new targets are set.

The person responsible for the internal review should be known beforehand, for example the veterinarian. At the same time, it is necessary to indicate on the internal review who is responsible for making certain proposed adjustments.

\section{Documents in the Quality Risk Management Program (Step 11 in Table 1; Chapter 8 of the Handbook)}

Examples of documents heading under the HACCPconcept have been given above and can be found in detail in [7] and on the vacqa-international.com website [9].

It must be clear that there is a certain overlap between those records that are applied in Herd Health and Production Management programs [10], and those implemented in a HACCP-like program of Quality Risk Management [11]. When both programs are integrated properly, the purposes of both programs too can be integrated as well as their documents. Nevertheless, when one has to prove that the HACCP-like program is currently running, then the necessary documents as presented above must be available to the auditing party on formal grounds. In addition, under a HACCP-like program, additional documents must be made available. Among these are: reports from laboratory examinations (bacteriology; serology; virology; myco-toxicology, etc); reports from postmortem examinations; reporting forms like event logs; incidence reports; improvement sheets; purchase logs; delivery complaint logs; problem analysis reports.

In the elapse of a HACCP-like quality risk management program over time, events such as diseases will occur. Such events may be relevant for the maintenance of the program but they may also be important for operational farm management. They need therefore, to be recorded. This should be done in an events log, which is a farm diary [10] or in a special Incidence Report. Threshold values in different subcategories can be used for and fine-tuned consecutive years. Incidence Reports are directly impacting on the stability of a quality risk management program, for example because they reflect a point (CCP or POPA) where quality control was lost or where a hazard (a disease) has occurred. It is paramount to keep incidence reports because they may trigger adjusting the monitoring scheme or even the quality risk management program as a whole.

\section{DISCUSSION AND CONCLUSIONS}

Food animal production, like the one on dairy farms, represents the first link in a (dairy) food chain quality assurance program. When most of the links in such a food chain have been certified for quality control measures, it is rather peculiar that the first link has received relatively little attention over the past years. Although the control of milk quality has a longstanding history, attention for the production process itself has increased only recently, not in the least due to changing consumer behavior and opinion, and to outbreaks of highly contagious diseases extensively addressed in the 
Table 7. Example of a Particular Dairy farm Calendar for Health and Nutrition Issues

\begin{tabular}{|c|c|c|c|c|c|c|c|c|c|c|c|c|}
\hline & Jan & Feb & March & Apr & May & Jun & Jul & Aug & Sept & Oct & Nov & Dec \\
\hline \multicolumn{13}{|l|}{ CMT* herd screening } \\
\hline \multicolumn{13}{|l|}{ Herd hoof trimming } \\
\hline \multicolumn{13}{|l|}{ Foot bathing with one authorized product } \\
\hline \multicolumn{13}{|l|}{ Lungworm vaccination } \\
\hline \multicolumn{13}{|l|}{ Screen rearing young stock } \\
\hline \multicolumn{13}{|l|}{ Check barn climate } \\
\hline \multicolumn{13}{|l|}{ Check on liver fluke } \\
\hline \multicolumn{13}{|l|}{ Check on ectoparasites } \\
\hline \multicolumn{13}{|l|}{ Start calves in pasture } \\
\hline \multicolumn{13}{|l|}{ Evaluation pasturing cows } \\
\hline \multicolumn{13}{|l|}{ Suppl. feeding at pasturing } \\
\hline \multicolumn{13}{|c|}{ Feeding management at change from pasture to barn } \\
\hline \multicolumn{13}{|l|}{ Roughage analysis } \\
\hline \multicolumn{13}{|l|}{ Barn feedstuff balance } \\
\hline \multicolumn{13}{|l|}{ Evaluation barn feeding } \\
\hline \multicolumn{13}{|l|}{ Check concentrate automates } \\
\hline Estimate \# kgs of concentrates $/ 100 \mathrm{~kg}$ milk & & & & & & & & & & & & \\
\hline
\end{tabular}

*CMT: California Mastitis Test, for detection of subclinical mastitis.

media. Quality should refer to public health and food safety in the first place. However, both forenamed are often influenced by the way that animal health and welfare are managed on the farm. Moreover, consumers have shown an increasing concern about animal health and welfare.

The classical veterinary approach to disease is either a method of prevention (and eradication for highly contagious diseases) and control, or a policy of reducing disease prevalence (namely in the case of endemic diseases). For the latter, the diagnosis and treatment of individual cases, the curative approach, have been considered too costly and too much impacting on animal welfare. Over the last decades, there is a growing tendency to pay more attention to prevention (e.g. by vaccination programs or deworming protocols), and over the last years to risk identification and risk management. Herd health and production management programs, HHPM, as presented in literature $[10,11]$ address all these issues, but still in a rather qualitative and non-formalized approach. These HHPM often are lacking structure, organization and planning being executed in a too much "free-style" manner.
This can be a major factor of the failures encountered in HHPM, although overall farm management benefits from the implementation of HHPM and it has been shown that also economic benefits are to be expected from HHPM [10, 12, 13].

The key words of HACCP-like QRM are structure, organization, planning, communication and formalization, as was shown through the examples of Figures and Tables above [7]. Hence, such QRM fill the gaps noted at HHPM. QRM and HHPM have several similarities, but the fact that in QRM the activities are protocol-based, well structured in time and place, properly planned, and -most importantlyformalized, leads the QRM approach promises much more benefits and effect than current HHPM can accomplish. A merger between the two would be best, profiting from both the operational (economics and) management focus (HHPM) and the more tactical farm focus (QRM). The QRM as proposed here is quite feasible on farm level. Farmers apparently adopt the QRM because it has a 'bottom-up' focus and not a top-down; it is highly farm-specific, integrating farm 
management and quality control in one approach. Farmers experienced in this QRM approach state that they are much more focused on problem areas and risk factor profiles through the formalized QRM approach. They experience that they do not tend to neglect or forget relevant issues; they feel well guided along the whole pathway to problem solution and along routine herd inspection (monitoring).

Because the demonstration to third parties (e.g. animal food suppliers; retailers; authorities; consumers), of the herd status regarding food safety, public health and welfare, as well the measures taken to improve that status, are formal part of the HACCP concept, the consumers can be provided with much more certainty about the quality of the products and the production methods on the dairy farm, provided that the food suppliers also participate in the dairy food chain quality assurance system. Such QRM largely contributes to the transparency of the on-farm production and the openness to society. This will contribute to the positive public image of the dairy (farming) sector.

Veterinarians should play a paramount role in this domain; First, because they have been properly educated in the various areas; Secondly, because they have experience in this domain; Thirdly, they have easy access to the dairy farms and can make frequent visits when needed [14]. As was shown above, following the different chapters in the HACCP Handbook, the veterinarian can indeed play a paramount role in all the QRM related components, not in the least because he could very well serve different clients from one source of digital HACCP-like templates (sheets) which he can easily adapt to specific needs of each particular dairy farm.

For developing and implementing HACCP-like QRM, inexperienced veterinarians have to acquire additional knowledge and skills (farm economics; nutrition; marketing and business administration; communication). However, once this was been done, veterinarians in the field will have a higher added value and benefit to the dairy farmers as coach and consultant in quality control according to HACCP-like Quality Risk Management, and hence contrib- ute to a more ensured food safety and public health where the dairy farm is concerned.

\section{REFERENCES}

[1] Cullor JS. HACCP (Hazard Analysis Critical Control Points): Is It Coming to the Dairy Farm. J Dairy Sci 1997; 80: 3449-3452.

[2] Noordhuizen JPTM. Dairy Herd Health and Production Management practice in Europe: state of the art. In: Proceedings $23^{\text {rd }}$ World Buiatrics Congress - Québec, Canada July 11-16, 2004

[3] Radostits OM. Bovine Practice: Successes of the Past, and Challenges and Opportunities in the Future. ${ }^{23 t d}$ World Buiatrics Congress - Québec, Canada. July 11-16, 2004.

[4] Vieira A, Boersema JSC, Noordhuizen JPTM, et al. The application of the Hazard Analysis Critical Control Points (HACCP) concept to a dairy farm in Portugal. Vet Rec 2008; in press.

[5] Cullor JS. Implementing the HACCP program on your clients' dairies. Vet Med 1995; X: 290-295.

[6] Lievaart JJ, Noordhuizen JPTM, van Beek E, et al. The hazard analysis critical control points concept as applied to some chemical, physical and microbiological contaminants of milk on dairy farms. Vet Q 2005; 27 (1): 21-29.

[7] Noordhuizen JPTM, Cannas da Silva J, Boersema JSC, et al. Applying HACCP-based Quality Risk Management on dairy farms. Wageningen Academic Publishers; 2008, Wageningen, The Netherlands.

[8] The Annex to the COAG/2003/6 - FAO, 2003, Rome, Italy.

[9] The website www.vacqa-international.com.

[10] Brand A, Noordhuizen JPTM, Schukken YH. Herd health and production management in dairy practice. Wageningen Academic Publishers; 1996, Wageningen, The Netherlands.

[11] De Kruif A, Mansfeld R, Hoedemaker M. Tierärztliche Herdenbetreuung beim Milchrind. Second Edition. Enke Verlag; 2007, Stuttgart, Germany (in German).

[12] Dijkhuizen AA, Morris RS. Animal health economics: principles and applications. University of Sydney, Australia, postgraduate formation in veterinary science, 1996.

[13] Huirne RBM, Saatkamp HW, Bergevoet RHM. Economic analysis of common health problems in dairy cattle. In: Proceedings of the XIIth World Buiatrics Congress (Kaske, Scholz and Holterschinken, editors), 18-23 August 2002; Hannover, Germany, 420431.

[14] Cannas da Silva J, Noordhuizen JPTM, Vagneur M, et al. The future of veterinarians in bovine health management. In: Proceedings of the World Buiatrics Congress (Navetat \& Schelcher, editors), Nice, France, October 2006. Also published in The Veterinary Quarterly; 1997; 28 (1): 28-33. 